\title{
Company profits from side effects of glaucoma treatment
}

A medication used to treat openangle glaucoma is being swept off pharmaceutical shelves because one of its side effects, longer eyelashes, has cosmetic appeal.

But other side effects of the drug bimatoprost - marketed by the California-based drug company Allergan as Lumigan for glaucoma patients and Latisse for those who desire eyelash growth - may outweigh the cosmetic benefits of longer, darker eyelashes. Those other side effects include eyelid swelling, discharge, blood seeping into the eye chamber, itching and irritation.

Another concern is that Latisse "can change the colour of the iris, so if people have blues eyes they can have some discoloration, a browning effect which can be permanent," says Dr. April Sanders, a skin and vein care physician based in Vernon, British Columbia.

But those are risks that many are prepared to take to achieve the cosmetic benefit of longer eyelashes, says Dr. Frederick Mikelberg, head of the department of ophthalmology and visual sciences at the University of British Columbia's faculty of medicine in Vancouver.

Even many taking bimatoprost for glaucoma find the eyelash effect appealing, Mikelberg says. "The men just laugh usually, and the women say 'fantastic'!"

Patients must sign informed consent forms before taking Latisse and it's recommended that it not be used by those already taking glaucoma drugs, so as to prevent doubling the bimatoprost dose.

Mikelberg adds that it's up to patients to weigh the risk of Latisse use. "If the public wants to use a medication for a cosmetic purpose, it's a choice."

That there are a host of people willing to take the health risks associated with bimatoprost to obtain longer eyelashes is evident in Allergan sales figures. The firm projected that it sold US\$90 million

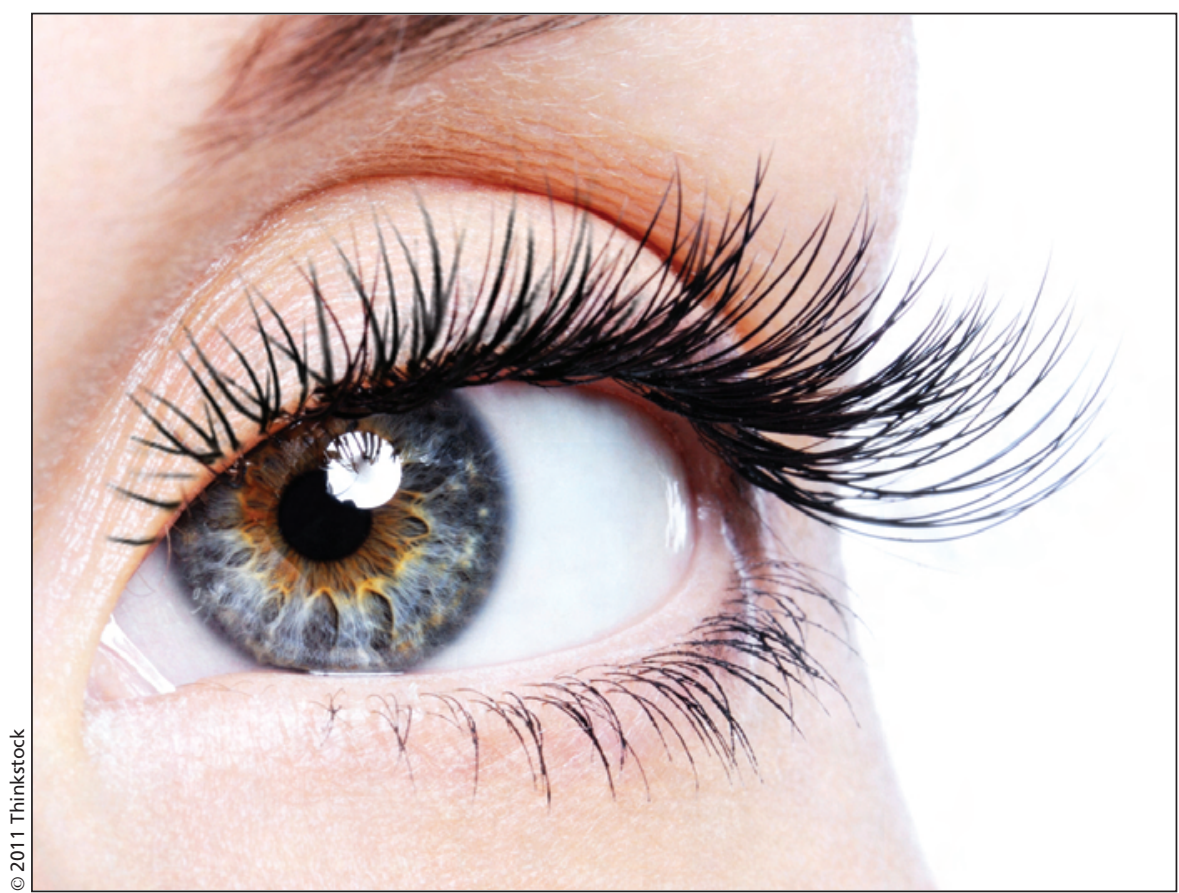

The side effects of the drug bimatoprost - eyelid swelling, discharge, blood seeping into the eye chamber, itching, irritation - may outweigh the cosmetic benefits of longer, darker eyelashes.

worth of Latisse in 2010 and about US\$520 million worth of Lumigan (http://agn.client.shareholder.com/release detail.cfm?ReleaseID=525350). There was a $35 \%$ increase in Latisse sales between September 2009 and September 2010, indicating that the "miracle" eyelash growing formula is becoming ever more profitable (http://files.shareholder .com/downloads/AGN/1285584035x0x 416372/8a11de62-12ad-459c-8044-dda 011996a18/110110\%20Q3\%202010\% 20Earnings\%20-Final\%20Charts.pdf).

A month's supply of Latisse costs Canadians about $\$ 120$, while the price of Lumigan varies according to insurance coverage but is about $\$ 75$ for $5 \mathrm{~mL}$ without insurance, says Sanders.

There's absolutely no difference between the two, says Mikelberg. "Same medicine, packaged differently." Lumigan is administered as an eyedrop, while Latisse comes with disposable wands used to line eyelashes daily.
Allergan says that when bimatoprost is used as Lumigan, it lowers pressure in the eye by aiding the flow of fluid out of the eye chamber, and when used as Latisse, it treats "eyelash hypotrichosis," which the firm defines as having "inadequate or not enough eyelashes" (www.allergan.com/assets /pdf/latisse_fact_sheet.pdf).

With Allergan using model Brooke Shields to flog Latisse, patient demand appears to be growing, Sanders says. "There has been some more print advertising I've noticed lately and so we certainly do have people inquire about it."

Latisse was approved for cosmetic use in Canada in 2010 "and found to have an acceptable risk-benefit profile," Leslie Meerburg, media relations officer for Health Canada, writes in an email. - Adrianna Banaszek, Coldstream, BC

CMAJ 2011. DOI:10.1503/cmaj.109-3919 